\title{
Radiation Damage Suppression in AISI-316 Steel Nanoparticles: Implications for the Design of Future Nuclear Materials
}

DOI:

10.1021/acsanm.0c01611

\section{Document Version}

Accepted author manuscript

Link to publication record in Manchester Research Explorer

Citation for published version (APA):

Aradi, E., Tunes, M., Lewis-Fell, J., Greaves, G., Antrekowitsch, H., Pogatscher, S., Donnelly, S., \& Hinks, J. (2020). Radiation Damage Suppression in AISI-316 Steel Nanoparticles: Implications for the Design of Future Nuclear Materials. ACS Applied Nano Materials. https://doi.org/10.1021/acsanm.0c01611

Published in:

ACS Applied Nano Materials

\section{Citing this paper}

Please note that where the full-text provided on Manchester Research Explorer is the Author Accepted Manuscript or Proof version this may differ from the final Published version. If citing, it is advised that you check and use the publisher's definitive version.

\section{General rights}

Copyright and moral rights for the publications made accessible in the Research Explorer are retained by the authors and/or other copyright owners and it is a condition of accessing publications that users recognise and abide by the legal requirements associated with these rights.

\section{Takedown policy}

If you believe that this document breaches copyright please refer to the University of Manchester's Takedown Procedures [http://man.ac.uk/04Y6Bo] or contact uml.scholarlycommunications@manchester.ac.uk providing relevant details, so we can investigate your claim.

\section{OPEN ACCESS}




\title{
Radiation Damage Suppression in AISI-316 Steel Nanoparticles: Implications for the Design of Future Nuclear Materials
}

\author{
Emily Aradi,* Matheus A. Tunes, Jacob Lewis-Fell, Graeme Greaves, Helmut Antrekowitsch, \\ Stefan Pogatscher, Stephen E. Donnelly, and Jonathan A. Hinks
}

Cite This: https://dx.doi.org/10.1021/acsanm.0c01611

Read Online

ACCESS

Llll Metrics \& More

Article Recommendations

Supporting Information

ABSTRACT: The self-healing capability of point and extended defects that are introduced by energetic particle irradiation is a desired behavior to be attained in the design and selection in potential materials for application in extreme environments. Nanoporous materials have a potential for achieving higher radiation tolerance due to the presence of many active unsaturable surfaces to which defects may diffuse and thus be effectively annihilated. The effects of heavy ion collisions in the lattice of functional AISI-316 steel nanoparticles (NPs) - which serve as a model for the ligaments in a nanoporous-are herein investigated

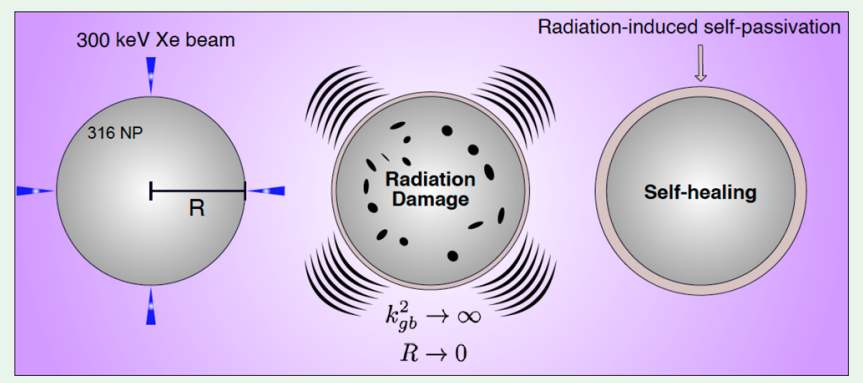
in situ within a transmission electron microscope. Comparisons are made directly with AISI-316 steel in the form of foils, and the results show that the fewer radiation-induced defect clusters form in the NPs and that small NPs $(r<50 \mathrm{~nm})$ were observed to accumulate fewer defects when compared to larger NPs. Post-irradiation analytical characterization within a scanning transmission electron microscope revealed that the AISI-316 steel NPs may develop a radiation-induced self-passivation driven by a solute-drag mechanism: an effect that can potentially enhance their radiation corrosion resistance in the expected extreme conditions of a reactor. The capability of an NP to self-heal irradiation-induced point defects is investigated using the cellular model for active internal and surface sinks. The design of functional nanoscale materials for extreme environments is discussed.

KEYWORDS: nanoporous materials, nanoparticles, radiation damage, ion irradiation, transmission electron microscopy

\section{INTRODUCTION}

The properties exhibited by 300 -series austenitic stainless steels such as high resistance to corrosion and creep have historically promoted the use of these steels as a structural material in current light water reactors (LWRs) and fast reactors. These austenitic stainless steels are also under consideration for application in advanced nuclear reactors such as Generations III ,$+ \mathrm{IV}$, and fusion reactors. ${ }^{1-5}$ The internal components of future nuclear reactors will be subjected to extreme service conditions of high radiation damage doses up to 80 displacements per atom (dpa), at elevated temperatures that pose a significant challenge for the design of future functional nuclear materials. ${ }^{6-11}$

In 1993 Lucas $^{12}$ assessed the overall effects of irradiation on the mechanical properties of austenitic stainless steels, and Garner ${ }^{13}$ recently reviewed the state of the art on their design and application in the nuclear industry with a particular focus on radiation damage effects. The majority of studies have reported that the formation of point defects such as vacancies, interstitials, and extended defects such as dislocation loops resulting from radiation damage induce extensive microstructural changes in the austenite phase. ${ }^{13-20}$ Radiation induced-segregation (RIS) and -precipitation (RIP) - which are unexpected chemical instabilities at a point defect sink such as a grain boundary or in the metastable austenite matrix-have been known to occur in 300-series steels ${ }^{21-31}$ and are considered to be the cause of many detrimental effects on their mechanical properties such as irradiation-assisted stress corrosion cracking (IASCC) and severe irradiation hardening. ${ }^{12,32,33}$ Transmutation products such as $\mathrm{He}$ (due to the presence of $\mathrm{Ni}$ in solid solution) and $\mathrm{Xe}$ (arising from nuclear fuels based on uranium) are known to induce the formation of nanometre-sized bubbles, whose growth can affect the dimensions of the structural components due to swelling. ${ }^{34-40}$ Eventually, the accumulation of displacement damage (e.g., manifested as dislocation loops and stacking faults) and inert gas bubbles (and voids) can cause severe embrittlement of the austenite matrix. ${ }^{20,31}$

Given the challenges associated with radiation damage buildup in the 300 -series stainless steels, it is clear that the existing materials solutions do not meet the requirements of

Received: June 12, 2020

Accepted: September 10, 2020 
Scheme 1. Schematic Illustration of the 316 Steel Sample Preparation using the Electropolishing Process

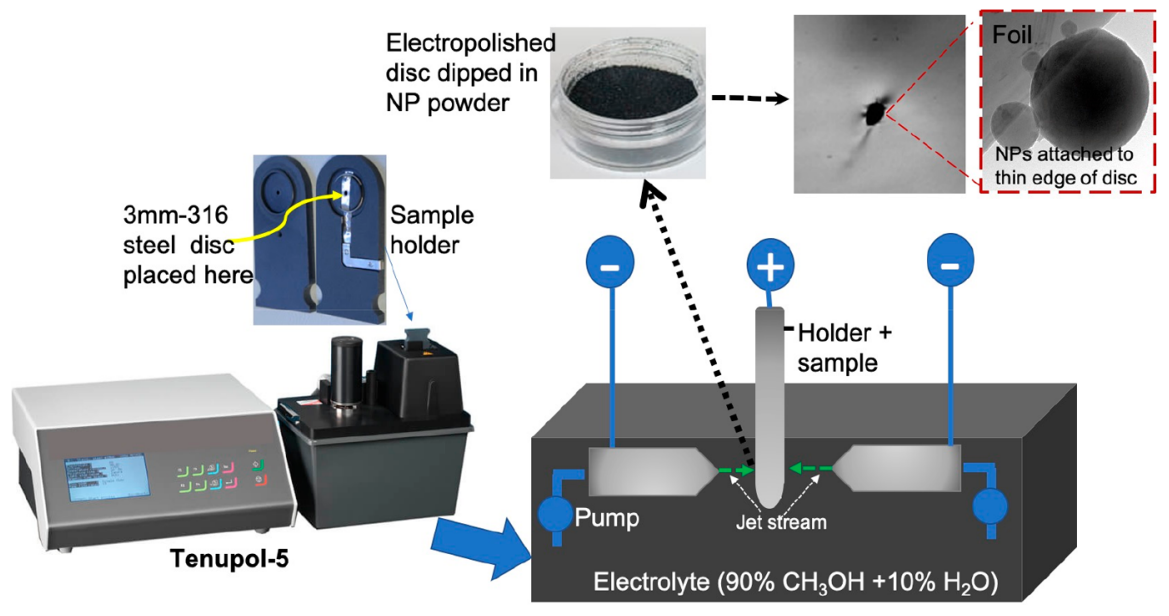

future nuclear reactors. The solution calls for the design of advanced materials tolerant to high radiation doses in the order of hundreds of dpa without significantly changing either their thermal or mechanical properties by controlling the damage buildup caused by atomic displacement and migration of defects. This remains a significant challenge, which has motivated numerous innovative approaches toward the design of radiation-resistant or immune materials. A field that is having a significant impact on the design of new materials is nanoprocessing, which allows metallurgists and materials scientists to manipulate the microstructure of alloys at the atomic scale. Most of the innovative radiation-resistant approaches exploit the use of different types of defect sinks, such as twin boundaries (TB), ${ }^{21,31}$ grain boundaries (GB), ${ }^{14,41-43}$ and phase boundaries (PB).

Ongoing studies have shown that nanoporous materials may exhibit enhanced radiation resistance ${ }^{17,44-47}$ due to their large surface area, which may be an unsaturable sink for point defects and their clusters and for the diffusion of gases from transmutation reactions. An idea that has been proposed regarding the development of nanoporous structural materials in nuclear fuels is that they are capable of alleviating fuel swelling caused by the accumulation of fission gas: ${ }^{45}$ a long-standing problem within the field. For nanoporous materials to have improved radiation tolerance, they require both that the defects have sufficient mobility to migrate to the surfaces and that the ligament morphology does not change drastically when subjected to energetic particle irradiation environments.

Transmission electron microscopy (TEM) with in situ heavyion irradiation is used in this study to track the real-time radiation damage effects on nanoparticles made of AISI-316 austenitic stainless steel, within the Microscope and Ion Accelerator for Materials Investigations (MIAMI facility ${ }^{48}$ ). These nanoparticles (NPs) were used as a model system to simulate individual ligaments of a hypothetical design of a nanoporous AISI-316 steel alloy. Such NPs have the advantage of revealing the behavior of individual ligaments without the interference of others, and as such the atomistic properties and changes of each ligament can be analyzed instantaneously. To establish a possible higher radiation tolerance of the AISI-316 NPs, the results were compared with irradiations carried out of an electron-transparent foil of the AISI-316 steel (used to represent a bulklike AISI-316) under identical irradiation conditions. Scanning transmission electron microscopy
(STEM) coupled with super-X energy dispersive X-ray spectroscopy (EDX) was used post-irradiation, to better understand the effects of the irradiation on the AISI- 316 NPs. The results obtained in this present work are discussed along with previous reports on the radiation tolerance of elemental metal nanoparticles in the context of the design for future functional nuclear materials including possible concerns arising around the recyclability of nanoengineered materials.

\section{EXPERIMENTAL SECTION}

2.1. Sample Preparation. The AISI-316 NPs were supplied by the American Element Company with sizes ranging from 30 to $150 \mathrm{~nm}$ in diameter, while the AISI-316 steel foils were obtained from the Alfa Caesar Company with both materials-foils and NPs-having the same nominal composition. Electron-transparent discs were prepared from the foils by electropolishing with an electrolyte solution made from $10 \%$ perchloric acid and $90 \%$ methanol using a TenuPol-5 jet electropolisher to a final thickness of $60-90 \mathrm{~nm}$ at the thinnest edges. The electrolyte bath temperature was kept below $243 \mathrm{~K}$ and an electric potential of $40 \mathrm{~V}$. The electropolished discs were then rinsed in three successive methanol baths and then left to dry in air before the NP powder was dispersed onto them. To avoid any "shadowing" of the ion beam during the irradiation experiments, only the NPs protruding at the thin edges of the foil and foil regions without the NPs were analyzed. Scheme 1 is an illustration of the processes involved in obtaining transparent samples used for the irradiation and TEM analyses.

2.2. In Situ TEM Ion Irradiation and Radiation Damage Calculation. In situ TEM experiments on the foils and NPs were performed using the MIAMI-2 system, ${ }^{48}$ which is composed of a 350 $\mathrm{kV}$ ion accelerator integrated with a Hitachi H-9500 TEM. The TEM is equipped with electron energy loss spectroscopy (EELS) and energyfiltered transmission electron microscopy (EFTEM) that were used for estimating the thicknesses of the foils. For the irradiations performed in the present work, a Xe ion beam with energy of $300 \mathrm{keV}$ was used. The average ion flux measured at the specimen position within the TEM was $1.3 \times 10^{13}$ ions $\cdot \mathrm{cm}^{-2} \cdot \mathrm{s}^{-1}$. The samples were at room temperature during the experiment and analyses.

The Stopping and Range of Ions in Matter (SRIM) Monte Carlo program $^{49}$ was used to calculate the damage density and implantation ion concentration for $300 \mathrm{keV}$ Xe ions in the AISI-316 samples. The SRIM program calculates the damage and ion distribution in the material by assuming an infinite length in the $Y$ and $Z$ directions, with a finite thickness in the $X$ direction. This works well for foil samples with large $Y$ and $Z$ directions compared to the sample thickness. When this approach is applied to spherical NPs, however, with their narrow and defined $Y$ and $Z$ dimensions, collision events may be calculated in volumes that the NP will not occupy, and the recorded results will be inaccurate. To account for the dimensions of the NPs, a Spherical Ion 

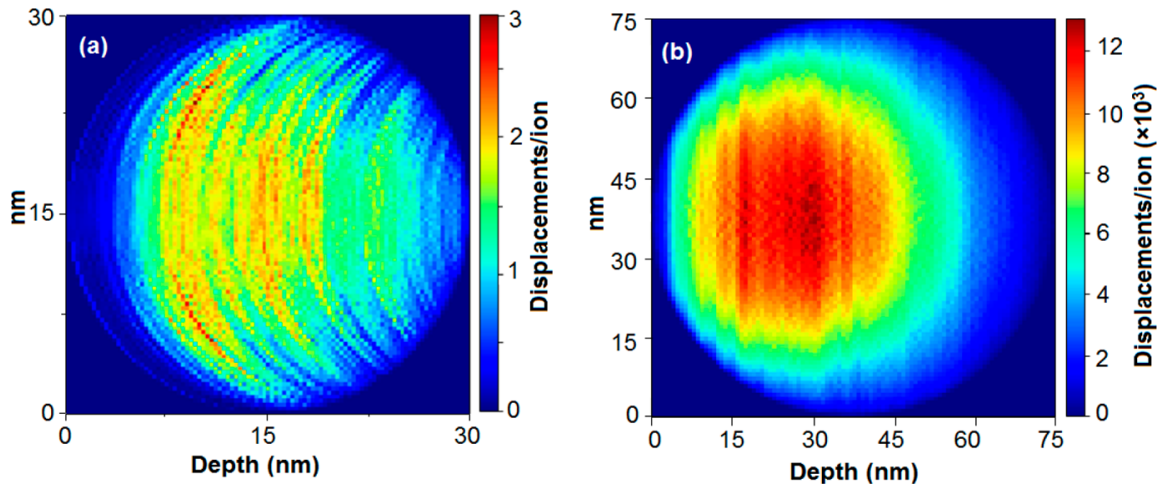

Figure 1. (a) SRIM-SICMOD reconstructed damage profile for AISI-316 NPs with diameters of (a) $30 \mathrm{~nm}$ and (b) $75 \mathrm{~nm}$ as irradiated with $300 \mathrm{keV}$ Xe ions.
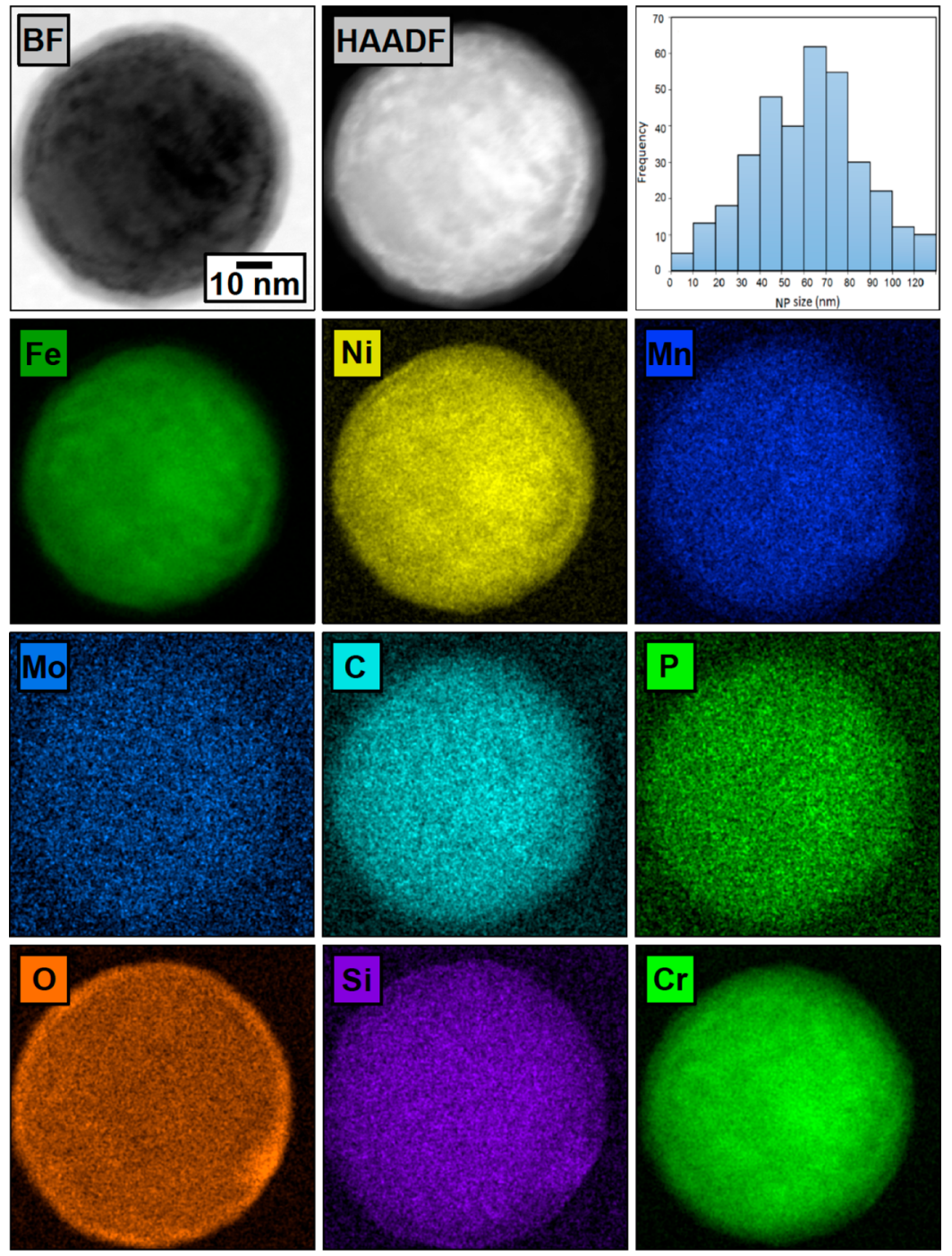

Figure 2. Pre-irradiation characterization of typical AISI-316 steel NP after dispersion in the austenite matrix. STEM-EDX analysis shows the elemental distribution of different elements within the NP as-dispersed. The histogram of size distribution for the AISI-316 steel NPs investigated in this study is also shown.

Calculation Modifier (SICMOD) Python script has been developed, the details of which can be found elsewhere. ${ }^{47}$

Figure 1 shows the SRIM-SICMOD damage profiles for (a) a $30 \mathrm{~nm}$ diameter AISI-316 steel NP and (b) a $75 \mathrm{~nm}$ diameter (the average radius measured in this work) AISI-316 steel NP. The damage densities were calculated using the stainless steel model from SRIM with displacement energy of $40 \mathrm{eV}$ using the "full cascade" damage calculation mode. The profiles reveal a variation in damage densities and distribution for the two NPs of different sizes, with the $30 \mathrm{~nm} \mathrm{NP}$ having a much lower damage density compared to that of the $75 \mathrm{~nm}$ $\mathrm{NP}$, due to the reduced probability of an incident ion stopping and depositing all its energy within the smaller NP. 
Table 1. Nominal and Measured Elemental Composition (wt \%) of the AISI-316 Steel Foil and NPs

\begin{tabular}{|c|c|c|c|c|c|c|c|c|c|}
\hline alloying element & $\mathrm{Fe}$ & $\mathrm{Cr}$ & $\mathrm{Ni}$ & $\mathrm{Mn}$ & Mo & $\mathrm{Si}$ & $\mathrm{C}$ & $\mathrm{Cu}$ & $\mathrm{P}$ \\
\hline AISI-316 (nominal) & Bal. & 18.8 & 14.0 & 2.0 & 1.6 & 0.59 & 0.09 & 0.09 & 0.04 \\
\hline AISI-316 (measured) & Bal. & $18.5 \pm 3.0$ & $10.8 \pm 1.7$ & $0.9 \pm 0.1$ & $2.7 \pm 0.5$ & $0.4 \pm 0.1$ & & & \\
\hline
\end{tabular}

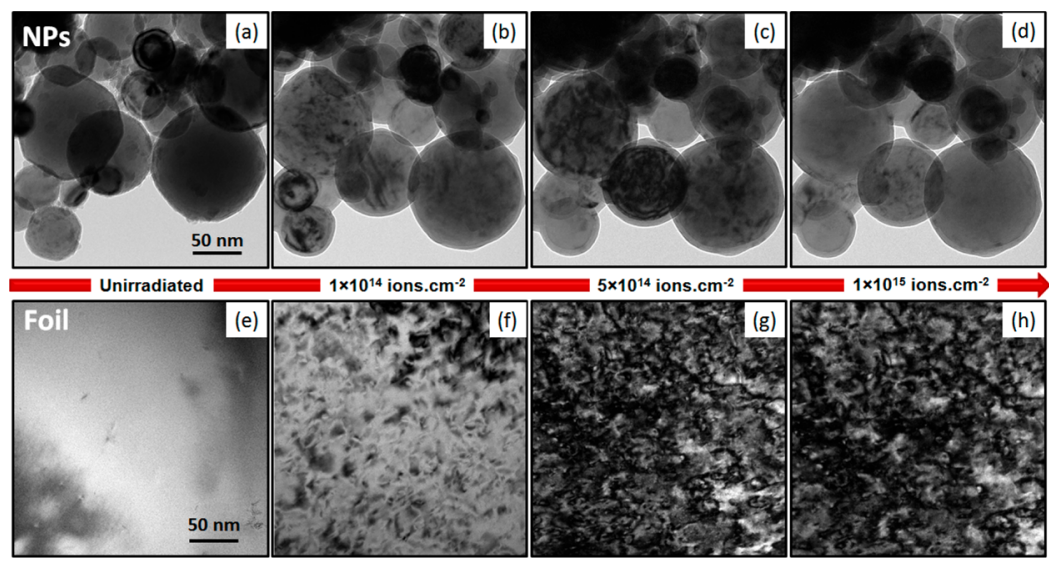

Figure 3. In situ BF-TEM images showing a progressive comparison of the microstructural evolution of (a-d) AISI316 steel NPs and (e-h) the AISI316 steel matrix irradiated with $300 \mathrm{keV}$ Xe at different fluences. Note: the scale bar in (a) applies to all the images.

2.3. Post-irradiation Characterization. After irradiation, samples were further characterized in a Thermo Fisher Scientific Talos F200X $\mathrm{S} / \mathrm{TEM}$ that uses a field-emission gun source and operates at $200 \mathrm{kV}$. The microscope is equipped with EDX super-X detectors for spectroscopy analysis, which was used to generate elemental maps of both the irradiated AISI-316 steel foil and the NPs. The high-angle annular dark-field (HAADF) and bright-field (BF) detectors were also used in STEM mode to image the AISI-316 steel NPs. Quantification of radiation-damage-induced extended defects such as the density of black dots (damage clusters) and dislocation loops was performed using the in situ TEM heavy-ion irradiation images from various NPs with an average diameter of $75 \mathrm{~nm}$ and by averaging measurements of different areas in the foil.

\section{RESULTS}

The present study was subdivided into pre-irradiation characterization, in situ TEM heavy-ion irradiation, and post-irradiation characterization of the AISI-316 steel NPs. The analyzed NPs were located at the edges of the specimen.

3.1. Pre-irradiation Characterization. Figure 2 shows TEM images of a typical AISI-316 steel NP before irradiation and a size distribution of the NPs that were analyzed. HAADF and BF images in Figure 2 reveal that the AISI-316 steel NPs self-passivate: a discrete and small enrichment of oxygen can be noticed at the surfaces with a thickness of $\sim 3 \mathrm{~nm}$. The histogram represents the size distribution (diameter) for 347 AISI-316 steel NPs that were analyzed in this study, with an average size of $\sim 75 \mathrm{~nm}$. The elemental analyses show that all the alloying elements are uniformly distributed throughout the NP, and neither segregation nor phase partition was observed. Using the STEM-EDX maps, it was possible to estimate the elemental composition of the AISI-316 steel NPs investigated in this work. Assuming an average diameter of $75 \mathrm{~nm}$ for an NP (and equal projected area in the foil), a density of $8.0 \mathrm{~g} \cdot \mathrm{cm}^{-3}$ and using the Brown-Powell ionization cross-section, ${ }^{49}$ the elemental composition of the AISI-316 steels is shown in Table 1. For comparison, the nominal composition of the AISI-316 steel as declared by the manufacturer is also shown.

3.2. In Situ TEM during Xe Ion Irradiation. Figure 3 shows a progressive evolution of the damage as a function of fluence in both AISI-316 steel NPs and the foils irradiated with $300 \mathrm{keV} \mathrm{Xe}$ ions at room temperature. Figure 3a,e represents the BFTEM images for the AISI-316 steel NPs and the foil before irradiation, respectively. Both NPs and the foil were observed to have a small density of pre-existing defects. The irradiationinduced microstructural changes in the NPs and foil are compared in Figure $3 \mathrm{~b}-\mathrm{d}$ and $3 \mathrm{f}-\mathrm{h}$, respectively, by using two sets of BFTEM images of the same regions obtained from in situ TEM heavy-ion irradiation at different fluences.

The experimental observations in Figure 3 focus on the evolution of dislocation loops and their population (referred to as number density in the subsequent text) as a function of fluence in AISI-316 steel NPs and the foils. At the beginning of the irradiation-at a fluence of $1 \times 10^{14}$ ions $\cdot \mathrm{cm}^{-2}$ - as seen in Figure $3 b$, there is an emergence of defect clusters and dislocation loops in the NPs. As the fluence increases (Figure $3 c)$ the number density of these loops increases, but at the highest fluence analyzed- $1 \times 10^{15}$ ions $\cdot \mathrm{cm}^{-2}$ - there are only a few scattered dislocation loops observed in some of the NPs as shown in Figure 3d: at the end of the irradiation, most of the dislocation loops formed within the AISI-316 steel NPs have vanished. Over the entire irradiation experiment (as observed in the in situ TEM Xe ion irradiation, video 1) it was observed that, as soon as the defects form in the NPs, they start migrating to the nearest surface.

This process of formation and absorption of dislocation loops at surfaces was observed to be continuous during the entire irradiation process in all the NPs. Similarly, at the beginning of the irradiation, defects with an elliptical-shaped loop are observed to form at a fluence of $1 \times 10^{14}$ ions $\cdot \mathrm{cm}^{-2}$ in the AISI-316 steel matrix as shown in Figure $3 \mathrm{f}$. At a fluence of $5 \times$ $10^{14}$ ions $\cdot \mathrm{cm}^{-2}$, a large number density of both elliptical loops dominates the microstructure of the austenite foil matrix phase, reaching a saturation point at $\sim 1 \times 10^{15}$ ions $\cdot \mathrm{cm}^{-2}$ as shown in Figure $3 \mathrm{~h}$. The in situ TEM Xe irradiation video (video 2 ) shows the rapid increase and saturation in the density of the dislocation loops with fluence in the foil matrix. The in situ videos also show reduced migration of the defects in the foil after their formation compared to the migration in the NPs at any particular fluence. 
Figure 4 shows a graphical comparison of the loop density in the AISI-316 NPs and foil as irradiated with $300 \mathrm{keV} \mathrm{Xe}$ at room

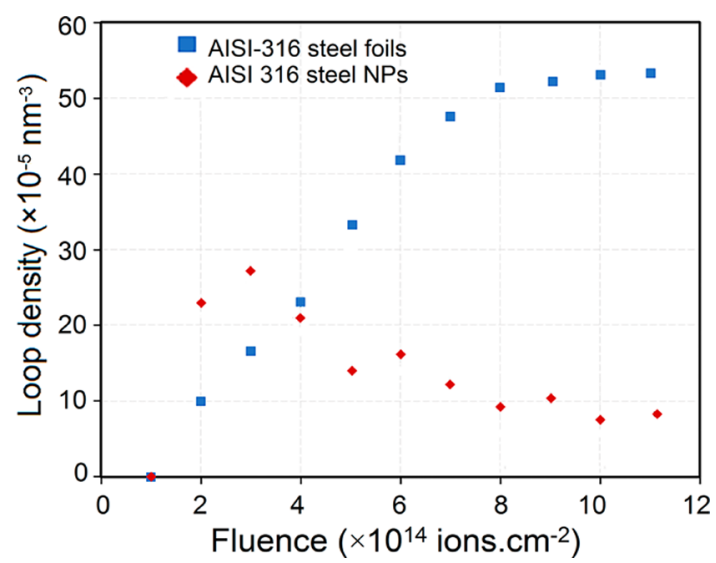

Figure 4. Experimental quantification of the radiation damage yield: estimated relationship between the dislocation loop density as a function of fluence for AISI-316 steel NPs and the foil irradiated with $300 \mathrm{keV} \mathrm{Xe}$ ions at room temperature. The loop density was calculated by taking the total number of defects in all the NPs measured and dividing this by the sum of all the projected areas of the individual NPs (and equivalent area in the foil matrix) to give the average loop density.

temperature as a function of fluence. The data were obtained for irradiations performed to a maximum fluence of $1.2 \times 10^{15}$ ions. $\mathrm{cm}^{-2}$ (total irradiation time $t=100 \mathrm{~s}$ ), as the saturation in density and the complex geometry of the defects in the foils at longer irradiation exposure times render it nearly impossible to obtain reliable measurements. For each fluence, the total loop density, denoted as $\rho_{\mathrm{L}}$, was calculated using eq 1

$$
\rho_{\mathrm{L}}=\sum\left(\frac{N_{\mathrm{L}}}{V_{\mathrm{P}}}\right)
$$

where is the $N_{\mathrm{L}}$ is the number of loops counted within a projected area as viewed in the TEM image, and $V_{\mathrm{p}}$ is the volume associated with the projected area of the observed/counted loops. The total number of loops was counted from the projected areas of 92 randomly distributed NPs with sizes ranging between 35 and $88 \mathrm{~nm}$ and from 92 different regions in the foil matrices with equivalent volume to the NPs.

The quantitative comparison data shown in Figure 4 indicated that defect density increased in the NPs for the first $2 \times 10^{14}$ ions $\cdot \mathrm{cm}^{-2}$. The number density then started to decrease at $\sim 3 \times$ $10^{14}$ ions $\cdot \mathrm{cm}^{-2}$ decreasing progressively with fluence, due to the defect-surface interaction, and as a result the NPs have a small population of defects at the end of the irradiation. In contrast with the AISI-316 steel NPs, the defect density in the foil matrix increased gradually with fluence, saturating at a fluence of $\sim 8 \times$ $10^{14}$ ions $\cdot \mathrm{cm}^{-2}$.

The displacement damage suppression process observed to occur in the AISI-316 steel NPs during irradiation can be better visualized in the BF-TEM images in Figure 5, which were extracted from the in situ TEM heavy-ion irradiation video (video 3). The arrows in the images of un-irradiated specimens (Figure 5a) show three different sized NPs (A, B, and C), where the defect creation, migration, and annihilation at the surface can be clearly seen from the beginning $(t=0 \mathrm{~s})$ up to the irradiation time of $t=40 \mathrm{~s}$. It can be seen after $5 \mathrm{~s}$ (fluence of $7 \times 10^{13}$ ions. $\mathrm{cm}^{-2}$ ) of irradiation that NPs A and B accumulate a large number of dislocation loops as shown in Figure $5 \mathrm{~b}$. The process of formation and diffusion of defects continues with increasing fluence, and at $t=40 \mathrm{~s}$ (end fluence of $5.9 \times 10^{14}$ ions $\cdot \mathrm{cm}^{-2}$; Figure $5 \mathrm{~h}$ ), the defect density in the NPs is observed to decrease significantly. It is worth noting that this process continues as long as the irradiation process goes on.

3.3. Post-Irradiation Characterization. STEM-EDX was used to perform high-magnification elemental mapping of the AISI-316 steel NPs after irradiation. Figure 6 shows a set of elemental maps obtained from an NP irradiated to a fluence of $3.5 \times 10^{16}$ ions $\cdot \mathrm{cm}^{-2}$ (corresponding to $138 \mathrm{dpa}$ ). A layer rich in $\mathrm{O}, \mathrm{Si}$, and $\mathrm{Cr}$ is noted at the surface of the NP. Apart from this layer, RIP was not observed to occur within the NPs of the irradiated samples analyzed in this work. Another experimental
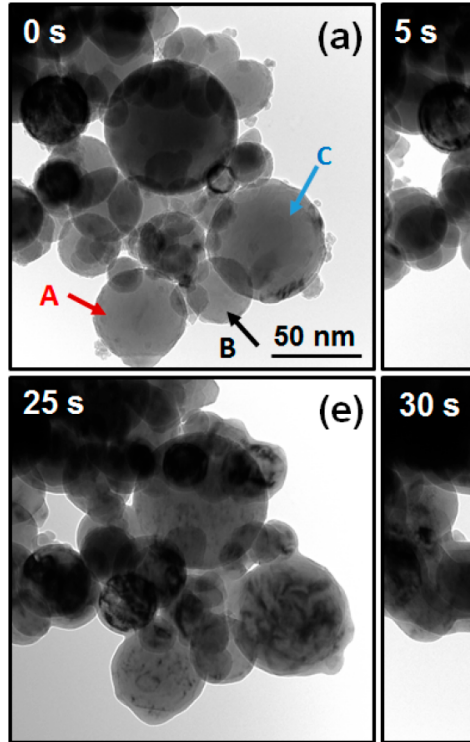
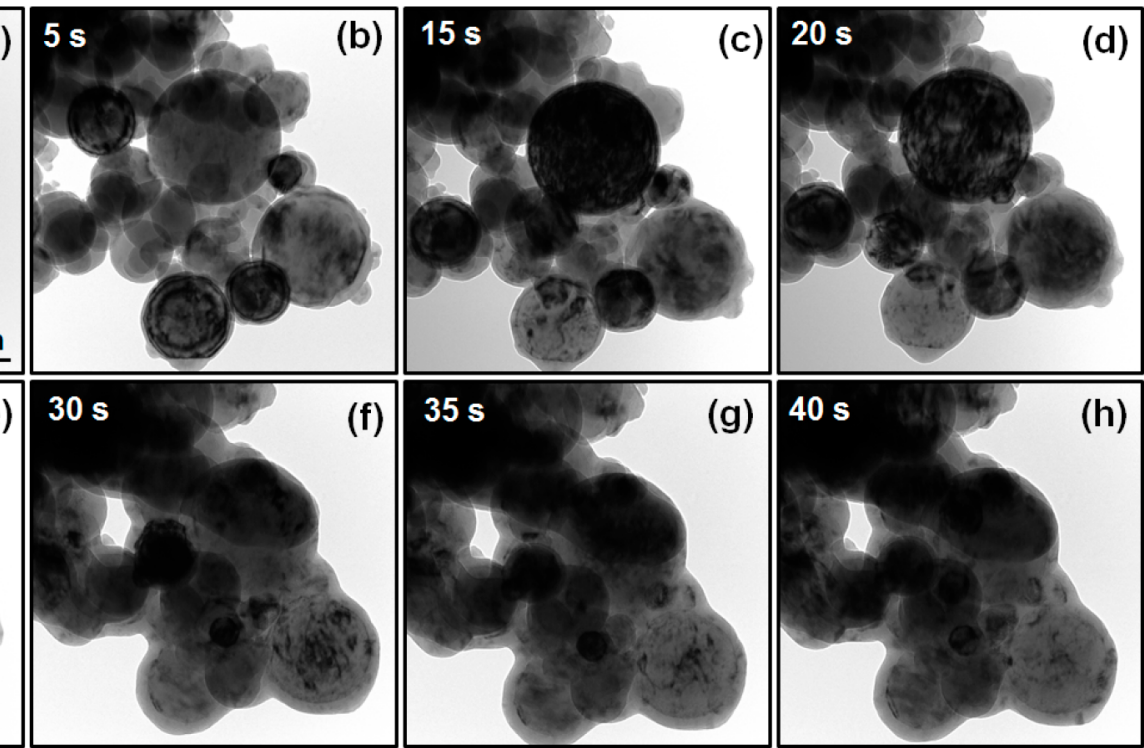

Figure 5. BF-TEM images extracted from the in situ TEM ion irradiation videos showing the evolution of displacement damage in AISI-316 steel NPs: (a) before irradiation with the arrows pointing at three NPs of interest, $(b-h)$ the formation, migration and annihilation of defect clusters at the surfaces as a function of irradiation time (and thus fluence). 

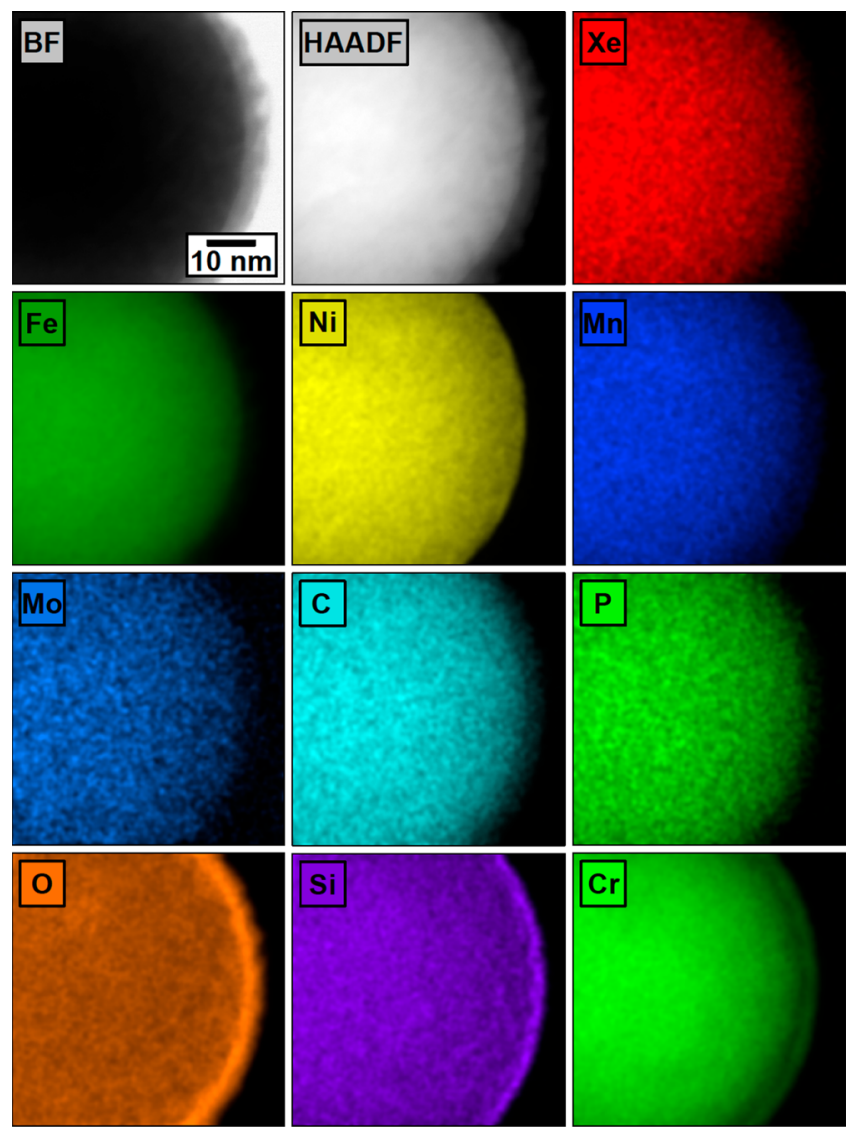

Figure 6. STEM-EDX post-irradiation characterization of the AISI-316 steel NPs. A slight enrichment of $\mathrm{O}, \mathrm{Si}$, and $\mathrm{Cr}$ is revealed at the surface of the NPs as a result of the irradiation. The irradiation dose is $138 \mathrm{dpa}$ corresponding to a fluence of $3.5 \times 10^{16}$ ions $\cdot \mathrm{cm}^{-2}$.

observation from the STEM-EDX maps is that Xe is uniformly distributed over the NP, and Xe bubbles were not observed to nucleate within the AISI-316 steel NPs under the irradiation conditions reported herein.

\section{DISCUSSIONS}

To estimate the evolution of radiation damage in polycrystalline materials in terms of sink strength for diffusing point defects, two models were historically studied and introduced by Brailsford, Bullough, and Hayns ${ }^{50-53}$ late in the 1970s. These were performed using Maxwell's formalism for the continuous representation of an inhomogeneous dielectric. ${ }^{54}$ During particle bombardment, it is well-known that external surfaces or internal grain boundaries of certain materials are sinks for point defects that are constantly generated as a result of lattice displacements caused by atomic collisions. Quantifying the strength of a defect sink is of paramount importance for the design of new materials to be used in future fusion and fission nuclear reactors, as damage buildup and accumulation can severely degrade them in both performance and reliability. ${ }^{55}$ Sink strength, in the current section, is used to quantify the efficiency of a sink to annihilate point defects.

A cellular model was initially developed, which considers an isolated spherical-shaped grain with radius $R$. In this model, there is no surrounding medium at the borders of the grain; thus, it assumes the presence of sink-free zones outside the surfaces, which in the present case is synonymous with isolated NPs. The sink strength considers only the internal ability to remove point defects that originated within the grain itself, leading to the definition of an internal sink strength $k_{\mathrm{sc}}{ }^{2}$. Aiming at deriving an effective surface sink strength-that is, $k_{\mathrm{gb}}{ }^{2}$ - the point defect concentration profile as a function of radius, $c(r)$, must be calculated from the continuity equation assuming the boundary conditions of $c=0$ at $r=R .^{53}$ Bullough et al. obtained an expression for grain boundary sink strength after estimating the point defect rates out of the grain $\left(\propto \frac{\mathrm{d} c}{\mathrm{~d} r}\right)$.

$$
k_{\mathrm{gb}}^{2}=k_{\mathrm{sc}}^{2}\left[\frac{k_{\mathrm{sc}} R \operatorname{coth}\left(k_{\mathrm{sc}} R\right)-1}{1+\frac{k_{\mathrm{sc}}{ }^{2}}{3}-k_{\mathrm{sc}} R \operatorname{coth}\left(k_{\mathrm{sc}} R\right)}\right]
$$

For the upper limit, where $k_{\mathrm{sc}} R \rightarrow \infty$ (i.e., larger grain sizes), the grain boundary sink strength is approximately

$$
k_{\mathrm{gb}}^{2} \approx \frac{3 k_{\mathrm{sc}}}{R}
$$

For the lower and asymptotic limit, where $k_{\mathrm{sc}} R \rightarrow 0$ (i.e., smaller grain sizes), the grain boundary sink strength is approximately

$$
k_{\mathrm{gb}}^{2} \approx \frac{15}{R^{2}}
$$

The cellular model concept adapted from ref 53 as well as the relationship between the grain boundary and internal sink strengths are shown in Figure $7 \mathrm{a}$. The plot in Figure $7 \mathrm{~b}$ emphasizes the existing competition between the grain boundary and internal sink strengths within the limits expressed by eqs 3 and 4 for a given grain size radius. As shown in the plot in Figure $7 b$, when the grain sizes are considered to be very large
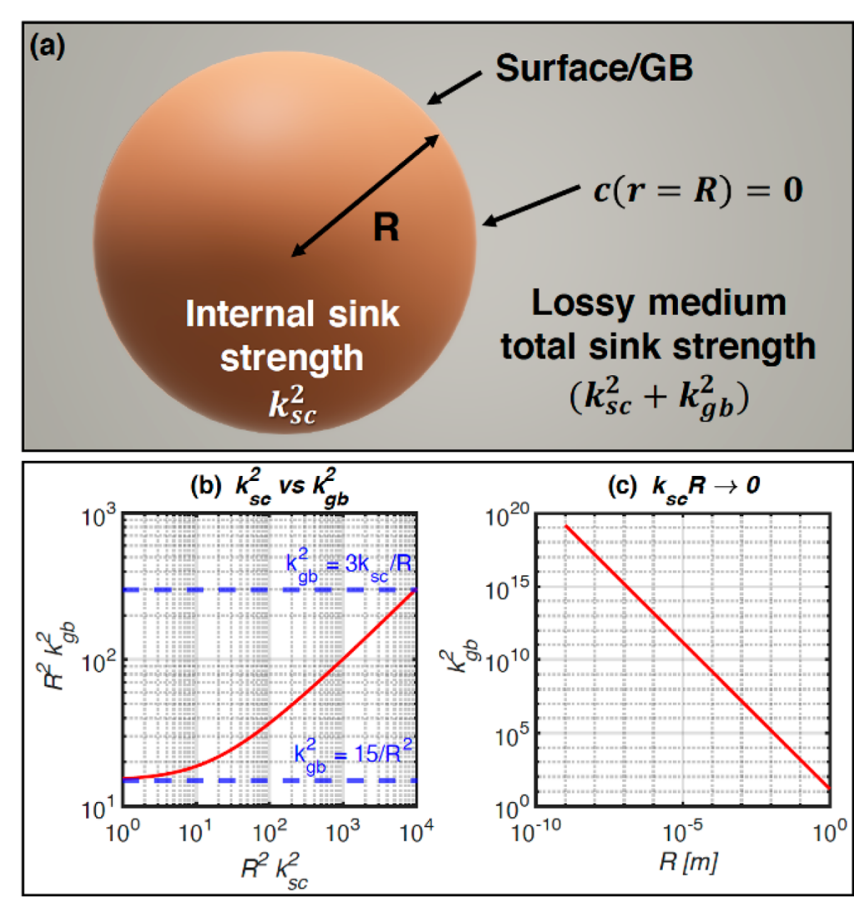

Figure 7. (a) The cellular model, which assumes a point defect flow only to the boundary, emanating from within the grain $\left(k_{\mathrm{sc}}{ }^{2}\right)$. The total sink strength of a grain is, therefore, $k_{\mathrm{sc}}{ }^{2}+k_{\mathrm{gb}}{ }^{2}$. This model can be considered to be equivalent to an NP of radius $R$. (b) Competition between grain boundary and internal sink strengths within the limits expressed by eqs 3 and 4. (c) Relationship between the grain boundary sink strength as a function of grain size within the limits expressed in eq 4 (Figure $7 a-c$ is an adaptation from Bullough et al. ${ }^{53}$ ). 


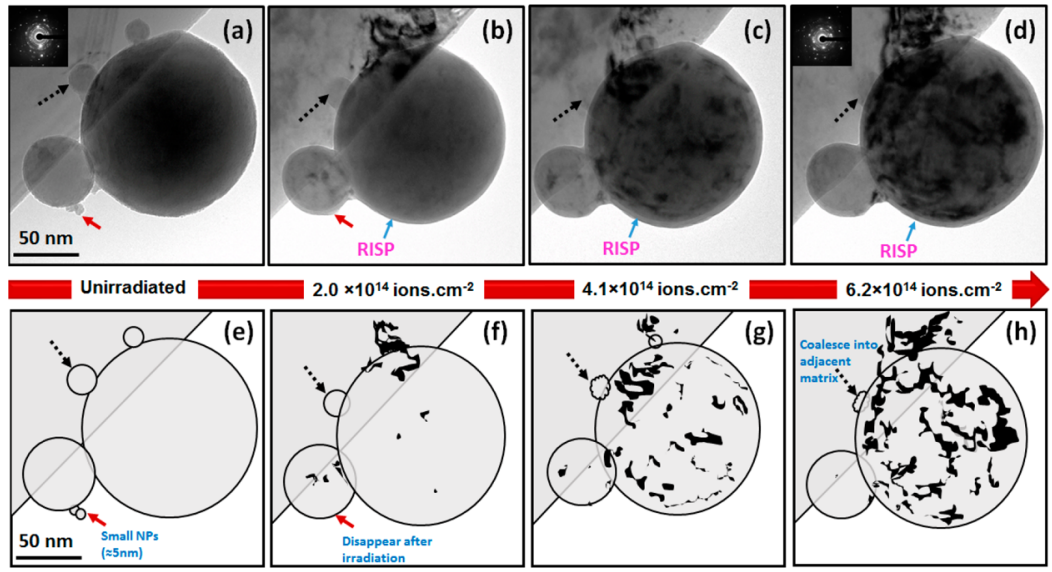

Figure 8. (a-d) BF-TEM images showing the defect evolution in $\sim 46 \mathrm{~nm}$ and $\sim 132 \mathrm{~nm}$ AISI-316 steel NPs. (e-h) The corresponding schematic illustrations showing both displacement damage accumulation and also the coalescence and sputtering of smaller AISI-316 steel NPs during irradiation. The red arrow is showing the sputtering effect, while the black-dashed arrow shows the coalescence. The blue arrow is indicating the formation of a passivation layer as a result of irradiation (the RISP effect).

(the limit expressed by eq 3), the internal sink strength dominates over the grain boundary sink strength by (at least) 2 orders of magnitude. Similarly, when the grain sizes are considered to be very small (the limit expressed by eq 4), the grain boundary sink strength is dominant over the internal sink strength and is also independent of the latter. Figure $7 c$ represents the relationship between the grain boundary sink strength as a function of size within the limits expressed in eq 4. In the lower asymptotic limit regime, the plot in Figure $7 \mathrm{c}$ shows that the grain boundary sink strength can assume values in order of $10^{20}$ when the grain sizes are in the nanometer scale, which decreases gradually with the increasing grain size.

Since the cellular model considers an isolated spherical grain, it can be assumed to be physically similar to a nanoparticle. For this reason, the surface of the NP can be represented by the grain boundary sink strength in eq 2 , thus allowing the cellular model to be used to interpret the results obtained in this work regarding Xe ion irradiation of AISI-316 steel NPs. A second model known as the embedding model (a refinement of the cellular model) calculates the flux of defects in and out of the grain assuming that there are no sink-free zones. Despite the difference in approach from the cellular model, Bullough ${ }^{53}$ analytically demonstrated that these two models are equivalent and converge within the limits expressed by eqs 3 and 4 . However, the embedding model is more accurate, and it is often used to derive sink strengths of other defect types such as voids and bubbles.

4.1. Radiation Damage Suppression. The results presented in this study show that there is significant displacement damage accumulation in the AISI-316 steel foil-while the AISI-316 steel NPs are able to "self-heal" the displacement damage buildup and hence are more radiation-tolerant. The in situ TEM heavy-ion irradiation technique was particularly suitable for observing the differences in both materials, as it provided a direct and real-time measurement of the effects of the materials under irradiation as shown in Figure 3. This technique was also useful in providing comparative quantitative data for the loop density (Figure 4): the results outline the continuous accumulation of damage within the foil with saturation at higher fluences; conversely, a peak in the damage-versus-fluence curve is observed for the NPs.

Clearly-due to the reduced sizes-large values for surfaceeffective sink strength can be expected for the AISI-316 steel
NPs as predicted by the cellular model within the asymptotic regime expressed by eq 2 . During irradiation, the generation of small black dots (defect clusters) and the subsequent formation and growth of dislocation loops will end with the loops annihilating at the surface, and thus the surfaces of the NPs can be considered very influential when the radiation resistance of NPs is a concern. The mobility of these defect clusters is also guaranteed provided the irradiation continues, as vacancyinterstitial pairs are constantly generated due to atomic collisions. As observed here, there is a continuous migration of clusters toward the free surfaces (video 3), which results in an overall reduction in the surviving displacement damage in the interior of the NPs.

Another consideration for the displacement damage selfhealing effect observed in this work lies in the fact that the density of dislocation loops generated within the NPs is high. A typical well-annealed metal has a volumetric density of dislocations of $\sim 10^{-9} \mathrm{~cm}^{-3} .{ }^{56}$ As expressed in the quantification plot shown in Figure 4, the loop density can be as large as $5 \times$ $10^{-11} \mathrm{~cm}^{-3}$ at the peak damage condition in the foil sample and up to $3 \times 10^{-11} \mathrm{~cm}^{-3}$ for the NPs. It has been reported that the activation enthalpy for dislocation diffusion at high temperatures is lower than the diffusion at low temperatures ${ }^{56}$ (the regime reported in this present study). Thus, the presence of a large number of dislocations in such a "nano-volume" significantly affects atomic diffusion within the AISI-316 steel NPs under irradiation, and in some situations, it may even be the dominant mode of transport (i.e., enhancing or even overcoming the contribution of vacancies). Under such irradiation conditions, neither Xe bubbles nor precipitates (RIP) were observed in the NPs after irradiation, as revealed by the BFTEM images in Figures 3 and 5 and in the STEM-EDX maps presented in Figure 7.

The synthesis of a bulk nanoporous structure has been developed by various researchers. Closely related to this work, $\mathrm{Fu}$ et al. ${ }^{57}$ synthesized bulk nanoporous $\mathrm{Au}$ foams using the dealloying process. Their study on the irradiation of these synthesized nanofoams was compared to the full dense material looking at the behavior of individual ligaments, and the results showed an enhanced tolerance in the nanoporous foams. Essentially, there will be less free surface in a nanoporous foam compared to individual ligaments. However, these surfaces are 
still large and will play a big role in providing enough sinks for radiation-induced damage; therefore, the forms will be more tolerant as compared to the bulk materials.

4.2. NP Size Dependence. It has been noted in the previous section that NPs up to $120 \mathrm{~nm}$ in diameter have an enhanced resistance to radiation damage due to the greater surface area that enables increased defect annihilation as opposed to the foil counterpart. This is also particularly interesting when one considers that the foil is also in the nanometer range in one direction, and thus it is expected that in bulk material there would be an even greater population of defects.

To demonstrate the role of NP size on the evolution of defect clusters in AISI-316 steel NPs, Figure 8 shows an example of microstructural changes in two NPs (46 and $132 \mathrm{~nm}$ in diameter) irradiated simultaneously with $300 \mathrm{keV}$ Xe ions at room temperature as a function of fluence. Figure $8 \mathrm{a}$ shows images of both NPs before irradiation with no pre-existing damage. After $4.1 \times 10^{14}$ ions $\cdot \mathrm{cm}^{-2}$ in Figure $8 \mathrm{~b}$, a low density of small defect clusters is observed to form in both NPs. At $6.2 \times$ $10^{14}$ ions $\cdot \mathrm{cm}^{-2}$ in Figure 8c, the defect density in the $46 \mathrm{~nm} \mathrm{NP}$ remains relatively constant, and defects are observed to migrate to the surface. Conversely, the defect density in the $132 \mathrm{~nm} \mathrm{NP}$ increases significantly with increasing fluence as shown in Figure $8 \mathrm{~b}-\mathrm{d}$. Note that, despite the high defect density within the matrix on the large NP, there is a significantly lower density near the surface $(\sim 10 \mathrm{~nm})$ in Figure $8 \mathrm{~d}$ as compared to Figure $8 \mathrm{c}$, as the near-surface defects migrate to the surface at the end fluence. Figure $8 \mathrm{e}-\mathrm{h}$ shows schematic illustrations of the defect evolution and accumulation of the phenomena observed in Figure $8 \mathrm{a}-\mathrm{d}$. Figure 8 is an illustration of the occurrences in both the NPs at equal fluences. Note that, at a particular fluence, the damage density in the smaller NPs is expected to be less than in large NPs. To ensure equal damage levels in both NP sizes, the small NPs were irradiated to a much higher fluence (made possible by in situ imaging at the required fluence) to get an equivalent dose. It was observed that even at high fluences the defect density in the small NPs was lower compared to the large ones, as the defects migrate to the nearest surface as soon as they form, as long as the irradiation process is in progress.

Generally, the number density of defects in the $132 \mathrm{~nm} \mathrm{NP}$ is still lower than in the foil at any particular dose. For NPs with sizes larger than $150 \mathrm{~nm}$, the defect accumulation approached those seen in the thin foils due a greater defect migration distance. Despite the fact that the defect density decreases with NP size, it was also observed that NPs less than $5 \mathrm{~nm}$ in diameter (red arrow in Figure 8a,e) are either sputtered or have coalesced with the larger NP during the irradiation process, as they were no longer visible soon after the first irradiation step. In another case, a smaller NP $(\sim 19 \mathrm{~nm}$ dashed arrow in Figure $8 \mathrm{e}, \mathrm{h})$ was observed to begin coalescing with the adjacent foil matrix after a fluence of $6.2 \times 10^{14}$ ions $\cdot \mathrm{cm}^{-2}$, implying that small ligaments in nanoporous materials may not be radiation-tolerant. On these latter findings, the enhanced diffusion due to irradiation may promote a reduction of surface energy, thus thermodynamically contributing to such dissolution of smaller NPs.

These results have shown that NPs within a particular size range are efficient in eliminating defects formed in the irradiation process, and such observations have also been reported by other authors studying other nanosystems. ${ }^{44,47,58}$ For instance, Bringa et al. $^{44}$ in their molecular dynamics (MD) simulation and experimental investigations on Ne irradiation in nanoporous $\mathrm{Au}$ reported that there exists a window within the nanoporous ligament size where radiation tolerance exists.

Below this size, the ligaments break, and above this size the ligaments respond to radiation damage in a similar manner to that of bulk. Biener et al. ${ }^{58}$ established an improved mechanical strength of $\mathrm{Au}$ nanoforms by decreasing the length scale of the ligaments using $\mathrm{MD}$ simulations and nanoindentation experiments on nanoporous Au. Thus, the length as well as the diameter of the nanoporous ligaments play an important role in increasing the radiation tolerance of the material in agreement with the cellular model for the strength of defect sinks for spherical grains. Evidently, the present experimental study points out that morphological irradiation effects such as coalescence and sputtering/evaporation have an NP size dependence; however, these phenomena have not yet been considered by the current sink strength models.

4.3. Radiation-Induced Self-Passivation. The growth of a passivation layer around the AISI-316 steel NPs during irradiation can be seen in Figures 3, 5, and 8. Under BF-TEM conditions, this layer is distinguishable from the NP core due to its particular contrast, different from the interior of the NP (further analyses of the layer using selected area diffraction pattern and dark-field TEM can be found in the Supporting Information). Post-irradiation characterization with STEMEDX in Figure 6 revealed that such a layer is formed mainly by $\mathrm{Cr}, \mathrm{Si}$, and $\mathrm{O}$ (and particularly depleted in $\mathrm{Ni}$ ). Figure $9 \mathrm{~b}$ shows a detailed net intensity plot of these elements from the interior to the surface of an NP indicated by the green arrow in 9a.
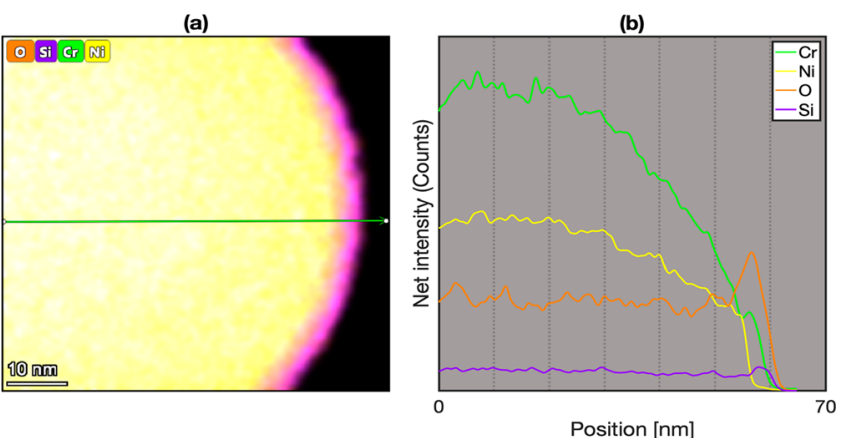

Figure 9. RISP phenomenon observed in an AISI-316 steel NP after irradiation (fluence of $3.5 \times 10^{16}$ ions. $\mathrm{cm}^{-2}$ ). (a) STEM-EDX elemental mapping for $\mathrm{O}, \mathrm{Si}, \mathrm{Cr}$, and $\mathrm{Ni}$ and (b) quantification profiles corresponding to the distance covered by the green arrow in (a). Segregation of $\mathrm{Cr}$ toward the surface induces the possible formation of a Cr-oxide layer in the AISI-316 steel nanoparticles under heavy-ion irradiation.

Elemental segregation has been observed to occur in austenitic stainless steels ${ }^{9,34-36}$ at defect sinks such as grain boundaries, twin boundaries, and dislocation loops, which has been attributed to the chemical instability of these elements at sinks. As no precipitates were observed to form within the AISI316 steel NPs, there is an indication that RIS has occurred at the NP surfaces as a result of accelerated diffusion toward the surface as a sink during irradiation but without the formation of precipitation phases (RIP). This phenomenon has been referred to in this study as radiation-induced self-passivation (RISP), and it may have occurred as a result of a chemical interaction of the diffusing $\mathrm{Cr}$ and $\mathrm{Si}$ atoms arriving at the surface of the NP with $\mathrm{O}$ atoms during the irradiation process to form a majorly $\mathrm{Cr} / \mathrm{Si}$ rich oxide. The source of $\mathrm{O}$ can be from the TEM vacuum system, which always contains a small partial pressure of oxygencontaining molecules. ${ }^{48}$ It has been reported that a depletion of 
$\mathrm{Fe}$ and an enrichment of $\mathrm{Cr}$ at sinks occurs because of the difference in solute exchange with vacancies during the irradiation process. $^{21,39}$ Interestingly, as noted by Garner, ${ }^{13}$ despite Si being a minor interstitial solute in 300 -series steels, it has a higher diffusivity than the major alloying elements $\mathrm{Fe}$ and $\mathrm{Ni}$, and therefore the $\mathrm{Si}$ interstitials can bind with solutes and vacancies from the austenite and drag them closer to an active sink. The observation of a Cr, Si-rich oxide layer in the AISI-316 NPs during irradiation suggests that they may undergo an irradiation-assisted solute-drag effect commonly observed in bulk materials. ${ }^{13,59-61}$ A study of the growth pattern of this layer on NPs of various sizes show that it self-limits; that is, it increases with increases in fluence reaching a maximum size of $\sim 10 \mathrm{~nm}$ (at a fluence of $\sim 3.5 \times 10^{14}$ ions $\cdot \mathrm{cm}^{-2}$ ), beyond which the size remains the same. These chemisorption phenomena may be particularly important within the context of NPs, as they are of superior surface-to-volume ratio when compared with bulk materials. Within the design of nanoporous materials, this RISP effect may be of particular importance when NPs are under consideration for application in extreme environments, as such a passivation layer can serve as a protective barrier against corrosion and related phenomena.

4.4. Nanoporous Materials Outlook for Nuclear Engineering and Recycling. A major factor to be considered when designing nanoporous materials for nuclear engineering is their proper disposal and potential recycling. The recycling process of nanomaterials is still a challenge of extreme complexity, and currently, only a limited number of laboratory-scale strategies have been developed aiming at the disposal, recycling, and reuse of nanomaterials. ${ }^{59-66}$ To the best of our knowledge, none of these strategies has been effectively established at an industrial scale. Furthermore, as recycling often involves the manipulation of materials using special solvents aimed at separation and recovery techniques, the RISP phenomenon observed above can further complicate this process, as the NPs may be resistant to strong chemical attacks.

Within neutron-irradiation environments, materials can be activated and become a source of radioactivity. The toxicityrelated problems associated with the exposure to nanomaterials are so far under-documented and incomplete. ${ }^{67}$ In the current case study, for example, AISI-316 steel contains elements that under neutron bombardment can transmutate to elements that spontaneously emit $\alpha$-particles. ${ }^{68}$ Therefore, radiologically activated AISI-316 NPs can deliver ionizing radiation, which can lead to extreme radiation exposure in case the nanomaterials are dispersed/released into the natural environment via the nuclear reactor coolant.

The superior radiation tolerance notwithstanding, if nanomaterials are to be engineered for use in nuclear power plants, their design should be followed by the development of a safe, specific, and effective way of recycling; otherwise, the health and safety concerns cannot be considered negligible in both the short and long terms. Clearly, the existing recycling protocols in metallurgy ${ }^{69,70}$ cannot be directly applied to nanomaterials, and thus the considerations and results presented in this paper are motivations for future work in the field.

Another significant concern on the use of nanoporous materials within nuclear reactors arises if they are considered as candidates for cladding the nuclear fuels: their inherent nanoporosity may expose the hot oxide fuels to primary coolants (e.g., pressurized water), which may either cause a plant shut down or, in the worst-case scenario, a nuclear accident.

\section{CONCLUSIONS}

Experiments using in situ TEM Xe ion irradiation at room temperature have verified that AISI-316 steel NPs are of superior radiation tolerance when compared with their AISI-316 steel foil counterpart. The sink strength of grain boundaries-as calculated by the cellular model-was used to interpret the observed results, where smaller NPs led to a greater self-healing effect in which black dots and small loops are formed and annihilated at the surfaces as the irradiation process continues. Complementary to the cellular model, it was discovered that the sink efficiency increased with decreasing size, where NPs with small diameters $(D<50 \mathrm{~nm})$ accumulated less damage as compared to the larger ones $(D>150 \mathrm{~nm})$. However, NPs with $D<20 \mathrm{~nm}$ were observed to sputter away or coalesce during the irradiation process. This implies that there exists a window in the NP size in which radiation tolerance exists. Together with the effective removal of displacement damage, post-irradiation characterization performed with STEM-EDX showed no voids, bubbles, or precipitate formation within the NPs following the Xe irradiations. Radiation-induced segregation of the AISI-316 steel NPs has shown a self-passivation phenomenon (now called RISP) under irradiation, where oxygen is present in the environment. This latter effect may play an important role in ensuring the NPs are resistant to corrosion.

If nanoporous materials are to be considered in the design of advanced power plants, their recyclability has yet to be demonstrated. This is of paramount importance for nuclear engineering, where the mitigation of activation and radioactivity reduction are major concerns.

\section{ASSOCIATED CONTENT}

\section{Supporting Information}

The Supporting Information is available free of charge at https://pubs.acs.org/doi/10.1021/acsanm.0c01611.

Further analyses of the NPs before and after irradiation (PDF)

Defect formation and distribution in nanoparticles (MP4)

Defect formation and distribution in foil (MP4)

Defect migration in NPs of different sizes (MP4)

\section{AUTHOR INFORMATION}

\section{Corresponding Author}

Emily Aradi - School of Computing and Engineering, University of Huddersfield, Huddersfield HD1 3DH, United Kingdom; School of Mechanical, Aeronautical and Chemical Engineering, University of Manchester, Manchester M13 9PL, United Kingdom; orcid.org/0000-0002-1549-5283; Email: Emily.Aradi@manchester.ac.uk

\section{Authors}

Matheus A. Tunes - Chair of Nonferrous Metallurgy, Montanuniversitaet Leoben, Leoben 8700, Austria; † orcid.org/ 0000-0002-5988-5363

Jacob Lewis-Fell - School of Computing and Engineering, University of Huddersfield, Huddersfield HD1 3DH, United Kingdom

Graeme Greaves - School of Computing and Engineering, University of Huddersfield, Huddersfield HD1 3DH, United Kingdom

Helmut Antrekowitsch - Chair of Nonferrous Metallurgy, Montanuniversitaet Leoben, Leoben 8700, Austria 
Stefan Pogatscher - Chair of Nonferrous Metallurgy, Montanuniversitaet Leoben, Leoben 8700, Austria

Stephen E. Donnelly - School of Computing and Engineering, University of Huddersfield, Huddersfield HD1 3DH, United Kingdom

Jonathan A. Hinks - School of Computing and Engineering, University of Huddersfield, Huddersfield HD1 3DH, United Kingdom

Complete contact information is available at:

https://pubs.acs.org/10.1021/acsanm.0c01611

\section{Notes}

The authors declare no competing financial interest.

\section{ACKNOWLEDGMENTS}

The authors are grateful to the Engineering and Physical Sciences Research Council for funding the MIAMI facilities under Grant Nos. EP/M01858X/1F and EP/M028283/1. Funding for this research was also provided by the European Research Council excellent science grant "TRANSDESIGN" through the Horizon 2020 programme under Contract No. 757961 and by the financial support from the Austrian Research Promotion Agency (FFG) in the project 3D nano-Analytics (FFG-No 858040).

\section{REFERENCES}

(1) Jublot-Leclerc, S.; Li, X.; Legras, L.; Lescoat, M. L.; Fortuna, F.; Gentils, A. Microstructure of Au-ion irradiated $316 \mathrm{~L}$ and $\mathrm{FeNiCr}$ austenitic stainless steels. J. Nucl. Mater. 2016, 480, 436-446.

(2) Pokor, C.; Brechet, Y.; Dubuisson, P.; Massoud, J.-P.; Barbu, A. Irradiation damage in 304 and 316 stainless steels: Experimental investigation and modeling. Part I: Evolution of the microstructure. J. Nucl. Mater. 2004, 326, 19-29.

(3) Mamivand, M.; Yang, Y.; Busby, J.; Morgan, D. Integrated modelling of second phase precipitation in cold-worked 316 stainless steels under irradiation. Acta Mater. 2017, 130, 94-110.

(4) Sun, X.; Chen, F.; Huang, H.; Lin, J.; Tang, X. Effects of interfaces on the helium bubble formation and radiation hardening of an austenitic stainless steel achieved by additive manufacturing. Appl. Surf. Sci. 2019, 467, 1134-1139.

(5) Sahin, S.; Ubeyli, M. A review on the potential use of austenitic stainless steels in nuclear fusion reactors. J. Fusion Energy 2008, 27, 271-277.

(6) Azevedo, C. R. F. Selection of fuel cladding material for nuclear fission reactors. Eng. Failure Anal. 2011, 18, 1943-1962.

(7) Abram, T.; Ion, S. Generation-IV nuclear power: A review of the state of the science. Energy Policy 2008, 36, 4323-4330.

(8) Yvon, P.; Carre, F. 'Structural materials challenges for advanced reactor systems. J. Nucl. Mater. 2009, 385, 217-222.

(9) Hosemann, P.; Vujic, J. Material issues for current and advanced nuclear reactor designs. Contemporary Materials 2014, 1, 10-25.

(10) Zinkle, S.; Was, G. Materials challenges in nuclear energy. Acta Mater. 2013, 61, 735-758.

(11) Tunes, M. A.; Greaves, G.; Kremmer, T. M.; Vishnyakov, V. M.; Edmondson, P. D.; Donnelly, S. E.; Pogatscher, S.; Schon, C. G. * Thermodynamics of an austenitic stainless steel (AISI-348) under insitu TEM heavy ion irradiation. Acta Mater. 2019, 179, 360-371.

(12) Lucas, G. E. The evolution of mechanical property change in irradiated austenitic stainless steels. J. Nucl. Mater. 1993, 206, 287-305.

(13) Garner, F. A. Radiation damage in austenitic steels. In: Comprehensive Nuclear Materials 2012, 4, 33-95.

(14) Radiguet, B.; Etienne, A.; Pareige, P.; Sauvage, X.; Valiev, R. Irradiation behavior of nanostructured 316 austenitic stainless steel. $J$. Mater. Sci. 2008, 43, 7338-7343.

(15) Tan, L.; Stoller, R. E.; Field, K.; Yang, G. Y.; Nam, H.; Morgan, D.; Wirth, B. D.; Gussev, M. N.; Busby, J. T. Microstructural Evolution of Type 304 and 316 Stainless Steels Under Neutron Irradiation at LWR Relevant Conditions. JOM 2016, 68, 517-529.

(16) Shang, Z.; Li, J.; Fan, C.; Chen, Y.; Li, Q.; Wang, H.; Shen, T.; Zhang, X. In-situ study on surface roughening in radiation-resistant ag nanowires. Nanotechnology 2018, 29, 215708.

(17) Shang, Z.; Li, J.; Fan, C.; Chen, Y.; Li, Q.; Wang, H.; Shen, T. D.; Zhang, X. Corrigendum: In-situ study on surface roughening in radiation-resistant Ag nanowires. Nanotechnology 2018, 29, 215708.

(18) Hojna, A. Overview of intergranular fracture of neutron irradiated austenitic stainless steels. Metals 2017, 7, 392.

(19) Tunes, M. A.; Vishnyakov, V. M. Microstructural origins of the high mechanical damage tolerance of nbtamow refractory high-entropy alloy thin films. Mater. Des. 2019, 170, 107692.

(20) Tunes, M. A.; Schon, C. G.; Greaves, G..* Radiation-induced precipitation with concurrent bubbles formation in an austenitic stainless steel (AISI-348). Materialia 2019, 7, 100408.

(21) Jin, H. H.; Lee, G. G.; Kwon, J.; Hwang, S. S.; Shin, C. The formation of radiation-induced segregation at twin bands in ionirradiated austenitic stainless steel. J. Nucl. Mater. 2014, 454, 28-36.

(22) Zheng, C.; Kaoumi, D. Radiation-induced swelling and radiationinduced segregation \& precipitation in dual beam irradiated Ferritic/ Martensitic HT9 steel. Mater. Charact. 2017, 134, 152-162.

(23) Sun, C.; Zheng, S.; Wei, C.; Wu, Y.; Shao, L.; Yang, Y.; Hartwig, K.; Maloy, S.; Zinkle, S.; Allen, T.; et al. Superior radiation-resistant nanoengineered austenitic 3041 stainless steel for applications in extreme radiation environments. Sci. Rep. 2015, 5, 7801.

(24) Zheng, C.; Auger, M. A.; Moody, M. P.; Kaoumi, D. Radiation induced segregation and precipitation behaviour in self-ion irradiated ferritic/martensitic ht9 steel. J. Nucl. Mater. 2017, 491, 162-176.

(25) Maziasz, P. J. The formation diamond-cubic phase in type 316 stainless steel exposed to thermal aging or irradiation environments. Scr. Metall. 1979, 13, 621-626.

(26) Maziasz, P. J.; McHargue, C. J. Microstructural evolution in annealed austenitic steels during neutron irradiation. Int. Mater. Rev. 1987, 32, 190-219.

(27) Maziasz, P. J. Formation and stability of radiation-induced phases in neutron-irradiated austenitic and ferritic steels. J. Nucl. Mater. 1989, $169,95-115$.

(28) Lee, E.; Maziasz, P.; Rowcliffe, A. Structure and composition of phases occurring in austenitic stainless steels in thermal and irradiation environments. In Symposium on Irradiation Phase Stability; Pittsburgh, PA, October 5, 1980; Oak Ridge National Laboratory, 1980; pp 191218. Online at https://www.osti.gov/scitech/biblio/5889791.

(29) Zinkle, S. J.; Maziasz, P. J.; Stoller, R. E. Dose dependence of the microstructural evolution in neutron-irradiated austenitic stainless steel. J. Nucl. Mater. 1993, 206, 266-286.

(30) Byun, T. S.; Farrell, K.; Lee, E. H.; Hunn, J. D.; Mansur, L. K. Strain hardening and plastic instability properties of austenitic stainless steels after proton and neutron irradiation. J. Nucl. Mater. 2001, 298, 269-279.

(31) Jin, S.; Guo, L.; Luo, F.; Yao, Z.; Ma, S.; Tang, R. Ion irradiationinduced precipitation of $\mathrm{Cr} 23 \mathrm{C} 6$ at dislocation loops in austenitic steel. Scr. Mater. 2013, 68, 138-141.

(32) Chopra, O.; Rao, A. A review of irradiation effects on LWR core internal materials - IASCC susceptibility and crack growth rates of austenitic stainless steels. J. Nucl. Mater. 2011, 409, 235-256.

(33) Was, G. S.; Allen, T. Intercomparison of microchemical evolution under various types of particle irradiation. J. Nucl. Mater. 1993, 205, 332-338.

(34) Maziasz, P. Effects of helium content of microstructural development in Type 316 stainless steel under neutron irradiation. In OSTI.GOV; Oak Ridge National Laboratory: Oak Ridge, TN, 1985. DOI: $10.2172 / 6441891$

(35) Watanabe, H.; Aoki, A.; Murakami, H.; Muroga, T.; Yoshida, N. Effects of phosphorus on defect behavior, solute segregation and void swelling in electron irradiated FeCrNi alloys. J. Nucl. Mater. 1988, 155, 815-822. 
(36) Okita, T.; Sekimura, N.; Garner, F. A. Effects of dpa rate on swelling in neutron-irradiated $\mathrm{Fe}-\mathrm{Cr}$ and $\mathrm{Fe}-\mathrm{Cr}-\mathrm{Mo}$ alloys. J. Nucl. Mater. 2011, 417, 944-948.

(37) Williams, T. M.; Titchmarsh, J. M.; Arkell, D. R. Void-swelling and precipitation in a neutron-irradiated, niobiumstabilised austenitic stainless steel. J. Nucl. Mater. 1982, 107, 222-244.

(38) Meric de Bellefon, G.; Bertsch, K.; Chancey, M.; Wang, Y.; Thoma, D. Influence of solidification-induced sub-granular structures on radiation-induced swelling in an additively-manufactured austenitic stainless steel. J. Nucl. Mater. 2019, 523, 291-298.

(39) Allen, T. R.; Cole, J. I.; Gan, J.; Was, G. S.; Dropek, R.; Kenik, E. A. Swelling and radiation-induced segregation in austentic alloys. $J$. Nucl. Mater. 2005, 342, 34290-100.

(40) Donnelly, S. The density and pressure of helium in bubbles in implanted metals: a critical review. Radiat. Eff. 1985, 90, 1-47.

(41) Rajan, P. B.; Monnet, I.; Hug, E.; Etienne, A.; Enikeev, N.; Keller, C.; Sauvage, X.; Valiev, R.; Radiguet, B. Irradiation resistance of a nanostructured 316 austenitic stainless steel. IOP Conf. Ser.: Mater. Sci. Eng. 2014, 63, 012121.

(42) El-Atwani, O.; Hinks, J. A.; Greaves, G.; Allain, J. P.; Maloy, S. A. Grain size threshold for enhanced irradiation resistance in nanocrystalline and ultrafine tungsten. Mater. Res. Lett. 2017, 5, 343-349.

(43) Zhang, Y.; Tunes, M. A.; Crespillo, M. L.; Zhang, F.; Boldman, W. L.; Rack, P. D.; Jiang, L.; Xu, C.; Greaves, G.; Donnelly, S. E.; et al. Thermal stability and irradiation response of nanocrystalline ecocrcufeni high-entropy alloy. Nanotechnology 2019, 30, 294004.

(44) Bringa, E. M.; Monk, J. D.; Caro, A.; Misra, A.; Zepeda-Ruiz, L.; Duchaineau, M.; Abraham, F.; Nastasi, M.; Picraux, S. T.; Wang, Y. Q.; Farkas, D. Are nanoporous materials radiation resistant? Nano Lett. 2012, 12, 3351-3355.

(45) Li, J.; Fan, C.; Ding, J.; Xue, S.; Chen, Y.; Li, Q.; Wang, H.; Zhang, $X$. In-situ heavy ion irradiation studies of nanopore shrinkage and enhanced radiation tolerance of nanoporous Au. Sci. Rep. 2017, 7, 110.

(46) Li, J.; Chen, Y.; Wang, H.; Zhang, X. In-situ study on enhanced heavy ion irradiation tolerance of porous Mg. Scr. Mater. 2018, 144, 13-18.

(47) Aradi, E.; Lewis-Fell, J.; Harrison, R. W.; Greaves, G.; Mir, A. H.; Donnelly, S. E.; Hinks, J. A. Enhanced radiation tolerance of tungsten nanoparticles to He ion irradiation. Nanomaterials 2018, 8, 1052.

(48) Greaves, G.; Mir, A.; Harrison, R.; Tunes, M.; Donnelly, S.; Hinks, J. New microscope and ion accelerators for materials investigations (MIAMI-2) system at the University of Huddersfield. Nucl. Instrum. Methods Phys. Res., Sect. A 2019, 931, 37-43.

(49) Ziegler, J. F.; Ziegler, M. D.; Biersack, J. P. SRIM - The stopping and range of ions in matter (2010). Nucl. Instrum. Methods Phys. Res., Sect. B 2010, 268, 1818-1823.

(50) Brailsford, A.; Bullough, R. The rate theory of swelling due to void growth in irradiated metals. J. Nucl. Mater. 1972, 44, 121-135.

(51) Brailsford, A. Diffusion to a random array of identical spherical sinks. J. Nucl. Mater. 1976, 60, 257-278.

(52) Brailsford, A.; Bullough, R.; Hayns, M. Point defect sink strengths and void-swelling. J. Nucl. Mater. 1976, 60, 246-256.

(53) Bullough, R.; Hayns, M.; Wood, M. Sink strengths for thin film surfaces and grain boundaries. J. Nucl. Mater. 1980, 90, 44-59.

(54) Maxwell, J. C. A Treatise on Electricity and Magnetism; Clarendon Press, 1881; Vol. 1.

(55) Zinkle, S. J.; Was, G. Materials challenges in nuclear energy. Acta Mater. 2013, 61, 735-758.

(56) Dislocation Pipe Diffusion; Springer Berlin Heidelberg: Berlin, Germany, 2007; pp 583-591. DOI: 10.1007/978-3-540-71488-0_33. (57) Fu, E. G.; Caro, M.; Zepeda-Ruiz, L. A.; Wang, Y. Q.; Baldwin, K.; Bringa, E.; Nastasi, M.; Caro, A. Surface effects on the radiation response of nanoporous Au foams. Appl. Phys. Lett. 2012, 101, 1-6.

(58) Biener, J.; Hodge, A. M.; Hayes, J. R.; Volkert, C. A.; ZepedaRuiz, L. A.; Hamza, A. V.; Abraham, F. F. Size effects on the mechanical behavior of nanoporous Au. Nano Lett. 2006, 6, 2379-2382.

(59) Deep, A.; Kumar, K.; Kumar, P.; Sharma, A. L.; Gupta, B.; Bharadwaj, L. M.; et al. Recovery of pure zno nanoparticles from spent zn-mno2 alkaline batteries. Environ. Sci. Technol. 2011, 45, 1055110556.

(60) Myakonkaya, O.; Guibert, C.; Eastoe, J.; Grillo, I. Recovery of nanoparticles made easy. Langmuir 2010, 26, 3794-3797.

(61) Myakonkaya, O.; Hu, Z.; Nazar, M. F.; Eastoe, J. Recycling functional colloids and nanoparticles. Chem. - Eur. J. 2010, 16, 1178411790.

(62) Pati, P.; McGinnis, S.; Vikesland, P. J. Waste not want not: life cycle implications of gold recovery and recycling from nano-waste. Environ. Sci.: Nano 2016, 3, 1133-1143.

(63) Li, C.; Liu, C.; Wang, W.; Mutlu, Z.; Bell, J.; Ahmed, K.; Ye, R.; Ozkan, M.; Ozkan, C. S. Silicon derived from glass bottles as anode materials for lithium ion full cell batteries. Sci. Rep. 2017, 7, 1-11.

(64) Yoon, T.-J.; Lee, W.; Oh, Y.-S.; Lee, J.-K. Magnetic nanoparticles as a catalyst vehicle for simple and easy recycling. New J. Chem. 2003, 27, 227-229.

(65) Yoon, H.; Ko, S.; Jang, J. Nitrogen-doped magnetic carbon nanoparticles as catalyst supports for efficient recovery and recycling. Chem. Commun. 2007, 14, 1468-1470.

(66) Nazar, M. F.; Shah, S. S.; Eastoe, J.; Khan, A. M.; Shah, A. Separation and recycling of nanoparticles using cloud point extraction with non-ionic surfactant mixtures. J. Colloid Interface Sci. 2011, 363, 490-496.

(67) Handy, R. D.; Shaw, B. J. Toxic effects of nanoparticles and nanomaterials: implications for public health, risk assessment and the public perception of nanotechnology. Health, Risk \& Society 2007, 9, $125-144$.

(68) Gaganidze, E.; Aktaa, J. Assessment of neutron irradiation effects on RAFM steels. Fusion Eng. Des. 2013, 88, 118.

(69) Stuhlpfarrer, P.; Luidold, S.; Antrekowitsch, H. Recycling of waste printed circuit boards with simultaneous enrichment of special metals by using alkaline melts: A green and strategically advantageous solution. J. Hazard. Mater. 2016, 307, 17-25.

(70) Herrmann, C.; Antrekowitsch, H.; Luger, T.; Seebacher, H.; Stachura, M. Product development and metallurgy combining two views on the calculation of recovery rates in WEEE recycling. In Proceedings of R'05-7th World Congress on Recovery, Recycling and Reintegration, September 25-29, 2005; Chinese Academy of Sciences, 2005. 